Journal of Patient-Centered

$1-19-2021$

\title{
The Silence of Food Insecurity: Disconnections Between Primary Care and Community Organizations
}

Nicole K. Runkle

David A. Nelson

Follow this and additional works at: https://aah.org/jpcrr

Part of the Community Health Commons, Community Health and Preventive Medicine Commons, Dietetics and Clinical Nutrition Commons, Family Medicine Commons, Medical Humanities Commons, Other Mental and Social Health Commons, Pediatrics Commons, and the Primary Care Commons

\section{Recommended Citation}

Runkle NK, Nelson DA. The silence of food insecurity: disconnections between primary care and community. J Patient Cent Res Rev. 2021;8:31-8. doi: 10.17294/2330-0698.1765

Published quarterly by Midwest-based health system Advocate Aurora Health and indexed in PubMed Central, the Journal of Patient-Centered Research and Reviews (JPCRR) is an open access, peer-reviewed medical journal focused on disseminating scholarly works devoted to improving patient-centered care practices, health outcomes, and the patient experience. 


\title{
The Silence of Food Insecurity: Disconnections Between Primary Care and Community Organizations
}

\author{
Nicole K. Runkle, MD, ${ }^{1,2}$ David A. Nelson, PhD $^{1}$ \\ ${ }^{1}$ Medical College of Wisconsin, Milwaukee, Wl; ${ }^{2}$ West Suburban Medical Center, Oak Park, IL
}

Purpose

Food insecurity is a prominent issue in the United States, and it is well established that food insecurity is linked to health and chronic illnesses. Studies show that screening for food insecurity is not yet part of standardized practice among all primary care physicians, nor are care providers comfortable with how to proceed with a patient who presents with this issue. Food insecurity is often handled by community-based organizations (CBOs) such as food pantries. Family medicine and pediatric clinics (FMPC) and CBOs hold unique relationships with their clients and can benefit from partnerships with each other to improve health in their community. The goal of this research was to better understand the connections between primary care and community organizations in addressing food insecurity.

Methods $\quad$ Focus groups and key informant interviews with FMPC providers and members of local CBOs (2 food pantries) were held from 2018 to 2019. Perceptions of participants regarding food insecurity were collected and analyzed concurrently using a grounded theory approach. Focus groups were transcribed and data analyzed for theme emergence.

Results A total of 39 participants took part in 4 focus groups (each with 8-10 participants) and 4 individual key informant interviews. The following themes emerged in both FMPC and CBO, in parallel yet separate ways: meaningful relationships; stigma; conversation starters; having the answers; safe spaces; and purposeful training.

Conclusions There is a disconnect between primary care and community organizations in regard to addressing food insecurity. FMPC and CBO could work together to create intentional intersections to address food insecurity and health in their shared populations. (J Patient Cent Res Rev. 2021;8:31-38.)

Keywords food insecurity; primary care; community-based organization; food pantry; provider perceptions; stigma; qualitative analysis

$\mathrm{F}$ ood insecurity is a prominent public health issue in the United States that impacts millions. ${ }^{1}$ According to the U.S. Department of Agriculture (USDA), food insecurity is defined as "times the food intake of one or more household members was reduced and their eating patterns were disrupted because the household lacked money and other resources for obtaining food." In 2017, the USDA reported that $11.8 \%$ of all U.S. households (15 million) and 7.7\% (2.9 million) of households with children were food insecure. ${ }^{1}$ Food insecurity is associated with negative health consequences and chronic illnesses such as poorer general health, cardiovascular disease, obesity, type 2 diabetes, hypertension, increased risk

Corresponding author: David A. Nelson, PhD, Department of Family and Community Medicine, Medical College of Wisconsin, 8701 W. Watertown Plank Road, Milwaukee, WI 53226 (danelson@mcw.edu) of birth defects, and greater risk of cognitive problems and mental health, along with increased health care utilization..$^{2-6}$

Due to the impact of food insecurity and social determinants of health on health disparities, there is a persistent need to address these issues. ${ }^{7}$ Food insecurity rates have risen during the COVID-19 pandemic, especially among children, with the long-term implications yet to be known. ${ }^{8}$ Armed with the knowledge that food insecurity and other social determinants of health impact health, an increasing number of organizations recommend that physicians and health care organizations become knowledgeable in screening for and ways to approach social determinants. ${ }^{7,-12}$ Although providers have become increasingly aware of this issue, and may have individually implemented screening or various programs, larger coordinated and standardized efforts are minimal. ${ }^{11,12}$ This is in part due to the lack of evidence surrounding referrals to community 
organizations and interventions based on screenings. ${ }^{13}$ In addition to a lack of evidence on the effectiveness of referrals, time constraints exist within health care that limit screening. ${ }^{14}$ Additionally, the ethical implication of properly addressing a positive screen can be intimidating. Despite the challenges of screening and referring patients to resources, primary care physicians understand the importance of their patients being food secure. ${ }^{15}$ Though innovation exists in primary care to approach these issues, more work needs to be done. ${ }^{10,16}$ Given these challenges, the intersection between individuals, health, primary care and community-based organizations (CBOs) needs to be further explored.

In the United States, a number of federal policy and community-based initiatives focus on decreasing food insecurity at the population and individual levels, respectively. ${ }^{17}$ Federal programs such as the Supplemental Nutrition Assistance Program (SNAP) ${ }^{18}$ and USDA child nutrition programs ${ }^{19}$ are means tested to support individuals and families who often experience high rates of food insecurity. A variety of CBOs, such as food pantries, food banks, and community gardens, also serve to address such social needs and have the resources and skills to do so. However, these groups, too, face time and resource constraints. ${ }^{7}$ For individuals who are food insecure, CBOs can serve as a vital source for food access ${ }^{20}$ and often fill the gap left by SNAP and governmental programs, an increasing necessity during the COVID-19 pandemic. $^{21}$ Traditional food pantries provide eligible households with food items designed to support the family over a prescribed number of days. ${ }^{22}$ Although food assistance programs were initially designed for temporary support, many clients rely on them for longer than 2 years. ${ }^{23}$ Despite the decline in the number of food-insecure individuals in the years preceding the pandemic, ${ }^{1}$ the amount of money needed to be food secure continues to increase. ${ }^{24}$ This gap may continue to widen as more individuals and families suffer from unemployment and food insecurity, requiring more financial support as a result of the pandemic. ${ }^{25}$

CBOs are positioned to engage the community under a variety of circumstances and contexts and are often seen as a gathering point, especially for low-income communities. ${ }^{26}$ To meet the needs of the community, CBOs need to build trust with the community and enter into partnerships that satisfy the principles of community engagement. ${ }^{27-29}$ CBOs help build to relationships in the community and often emphasize health in the biopsychosocial/spiritual dimensions. ${ }^{27}$ In addition to providing their defined services, CBOs often play important roles in advocacy and have the opportunity to strengthen health systems. ${ }^{26}$
However, despite the ability of CBOs to address food insecurity and the need for primary care providers to identify food insecurity in the clinical setting and connect patients to resources offered by $\mathrm{CBOs}$, CBOs often struggle to connect with health care systems. ${ }^{27}$ Limited communication exists between CBO staff and clinical practices, including collaboration regarding services related to food security. ${ }^{30}$ Thus, the purpose of this study was to explore the primary care and community perspectives of food insecurity and health, as well as the connections that exist between the primary care and community space in addressing food insecurity and health.

\section{METHODS}

Participants were recruited from 2 Milwaukee-based family medicine clinics and 1 pediatric health center (together termed "FMPC") and 2 Milwaukee-based nonprofit food pantry organizations (termed "CBO") to participate in focus group and key informant interviews in 2018-2019. Focus groups were aimed to have 8-10 individuals present. All interviews occurred during staff meeting times or usual organization operational hours and took place in private conference rooms at each respective facility. Inclusion criteria comprised the following: FMPC provider, CBO staff or frequent pantry client, and age of 18 years or older. All participants received lunch, and $\mathrm{CBO}$ participants received a $\$ 5$ gift card and bus pass for travel. All study activities were approved by the health system's institutional review board.

Before beginning, the facilitator distributed information and received questions regarding the research process, obtained verbal consent, and administered a demographic survey. Participants could decline to answer any questions and could withdraw at any time. Focus groups and interviews were audio-recorded and lasted approximately 60 minutes. FMPC participants were asked the following open-ended questions: "How does food insecurity fit in this space?" "How can we connect this place to a community-based organization, like a food pantry?" and "How can providers talk to their patients about food?" CBO participants were asked: "How does health fit in this space?" "How can we connect this place to health care?" and "How can people talk to their providers about having enough food?" Clarifying questions for elaboration and transitions were used throughout the session. Both authors were present during sessions and took field notes throughout for further review. Focus group and interview recordings were de-identified and transcribed verbatim.

The study was strategically designed to utilize qualitative methods, specifically focus groups, to best understand the perceptions of participants. Qualitative methodology is a flexible research tool that supports an understanding of 
the lived experience of the person being interviewed. ${ }^{31-33}$ To analyze the data, we used a grounded theory approach, which provides a set of flexible analytic guidelines to focus data collection and develop theories. ${ }^{34}$ Transcripts were iteratively coded to capture theme emergence by the authors and conferred for accuracy. Each theme was reflected in the focus group session. This process was like other qualitative research conducted by the team. ${ }^{35-38}$ Data collection and analysis occurred concurrently and regularly. This allowed for reflexivity at subsequent interviews, and data saturation was determined once no further themes emerged.

\section{RESULTS}

Four focus groups (of 8-10 participants each) and 4 individual key informant interviews, totaling 39 participants, were conducted. FMPC participants were predominantly White, female physicians in the 31-40-year-old age range. CBO participants were predominantly White, male volunteers. Of note, a good portion of $\mathrm{CBO}$ volunteers had previously been served by the food pantry. Participant demographics are fully displayed in Tables 1 and 2.

Six major themes were identified. These themes were more broadly categorized into 1) ways an individual impacts food insecurity and health, and 2) systemic influences. FMPC and CBO perspectives for each of the 6 themes are fully presented in Table 3 . These themes can be thought of as considerations for improvement at both primary care clinics and CBOs, with areas of identified success for both. Themes were represented in the narrative and transcripts of the participants, with illustrative quotes presented herein.

\section{Individual Impact}

Theme 1: Meaningful Relationships. Meaningful relationships represent bidirectional, trusted connections between individuals. All participants continuously returned to the importance of relationships. Providers with long-standing relationships with patients felt more comfortable discussing the issue. Similarly, the foundation of $\mathrm{CBO}$ s is the trusting relationships with their pantry clients, which allows discussion of sensitive issues. For example, one $\mathrm{CBO}$ participant noted:

"I think it has a lot to do with trust and having people comfortable with who they're talking to and being comfortable [at the CBO]."

Theme 2: Stigma. Stigma around food insecurity and health was repeatedly discussed throughout all interviews. FMPC participants acknowledged this as something that needs to be recognized and overcome. When prompted for further information, silence followed the question.
Table 1. CBO Survey Responses $(\mathrm{N}=10)$

\begin{tabular}{ll}
\hline Variable & $\mathbf{n}$ \\
\hline Gender & 6 \\
Male & 2 \\
Female & 2 \\
None declared & \\
Age & 2 \\
18-25 years & 4 \\
$31-40$ years & 1 \\
$41-50$ years & 2 \\
$51-64$ years & 1 \\
>65 years & \\
Race/Ethnicity & \\
White & 7 \\
American Indian & 1 \\
Other & 1 \\
None declared & 2 \\
Relation to CBO & \\
Volunteer & 9 \\
Pantry client & 2 \\
\hline
\end{tabular}

a One respondent identified as 2 different race categories.

${ }^{b}$ One respondent was both a $\mathrm{CBO}$ volunteer and client at the time of survey.

$C B O$, community-based organization.

Table 2. FMPC Survey Responses ( $\mathrm{N}=29)$

\begin{tabular}{lc}
\hline Variable & $\mathbf{n}$ \\
\hline Gender & \\
Male & 10 \\
Female & 19 \\
Age & \\
$26-30$ years & 6 \\
$31-40$ years & 15 \\
$41-50$ years & 1 \\
$51-64$ years & 6 \\
>65 years & 1 \\
Race/Ethnicity & \\
White & 20 \\
Black/African American & 4 \\
Hispanic or Latino & 1 \\
Asian & 4 \\
Relation to Facility & \\
Physician & 15 \\
Resident & 9 \\
Other & 5 \\
\hline
\end{tabular}

FMPC, family medicine/pediatric clinics. 
Table 3. Perspectives of Major Themes

\begin{tabular}{l|l|l}
\hline Individual impact & FMPC clinicians & CBO staff and/or clientele \\
\hline Theme 1: & $\begin{array}{l}\text { "You know, I think part of the relationship that } \\
\text { you have over the continuous time is it's a part of } \\
\text { their life and a part of what's going on for them } \\
\text { relationships } \\
\text { which, you know, they tend to tell me more, I } \\
\text { think, about just things in their life the more that } \\
\text { I know them whether they think it's related to } \\
\text { medicine or not." }\end{array}$ & $\begin{array}{l}\text { "I thint and having people comfortable with who they're } \\
\text { talking to and being comfortable." }\end{array}$ \\
\hline $\begin{array}{l}\text { Theme 2: } \\
\text { Stigma }\end{array}$ & $\begin{array}{l}\text { "And it's somewhat discomforting in that delving } \\
\text { into one's social stressors puts a burden on the } \\
\text { Whole session. So, I mean, it's sad to say that, } \\
\text { but that is how it is." }\end{array}$ & $\begin{array}{l}\text { I think, to tell people I don't have enough food. I } \\
\text { mean, even if you come here [food pantry], I think } \\
\text { this is in one way [how] they admit it." }\end{array}$
\end{tabular}

"Feeling as though you can't provide for yourself or you can't take care of yourself. ... And people look down on you when you can't take care of yourself or you don't have those basic needs or, like, housing. ... There's already kind of a stigma just in general with low income, low socioeconomic status, things of that nature."

Theme 3: $\quad$ "Most of our patients have WIC and food share

Conversation $\quad$ so we almost act like everybody does have it, as starters we always ask, like, 'Have you set your WIC up for babies yet?' and stuff like that."

"I wonder how many people also would think of this as a medical problem."

"I think for both the patient and the provider it's, okay, now we have uncovered this problem ... are they even gonna be able to help me with this? And you feel maybe guilty not knowing what you can actually do to help them, like maybe there is a food pantry but maybe they don't want to go there because of the stigma associated with going to it, I don't know. It seems like something that is almost like an unsolvable problem."

\section{Systemic impact}

Theme 5:

Safe spaces

\section{FMPC clinicians}

"A lot of the time it comes out spontaneously because of where they're at in their life and hopefully that they know this is a safe place for them."
"There's enough people that come in here that we know have health problems. I mean, they walk in, they tell us they have health problems ... and if we can get somebody that we could call and say, 'okay, this is what's going on; can you check them?' ... Maybe that would be a step toward them getting the real help that they need ... because medically we can't do it, but we can maybe start the walk.

"And insulin is how much a month now? It's ridiculous even if you have insurance, you know. So what's the point of knowing if you can't get what you need?"

\section{CBO staff and/or clientele}

"We have them [clients] already coming here and, I think, on a pretty good basis. We have a nice opportunity to get in touch with people and figure out what's wrong with them. We have their comfort and their trust in this space here "cause everyone knows it's inclusive. We are an inviting place here."

"So we're [pantry] trying to figure out a way ... we take them [health care volunteers at pantry] through some sort of motivational interviewing training, but like, all of those trainings, social science trainings, are designed around you getting out of the driver's seat a bit, getting out of your, suspending your judgments. ... What we would really love to see is some sort of collaborative where we could work with, so this is something that we put a lot of time and thought into ... to work on these approaches across disciplines. So whether l'm helping you go through an addiction or helping you bag groceries or helping you with your diabetes, like, we'll all kind of have a very similar approach and mindset.

CBO, community-based organization (ie, food pantry); FMPC, family medicine/pediatric clinics; WIC, U.S. Department of Agriculture's Special Supplemental Nutrition Program for Women, Infants, and Children. 
Stigma also became apparent when a provider discussed the "discomfort" of "delving into social stressors putting a burden on the whole session." CBO participants often described their experience facing stigma. A FMPC provider explained her understanding of stigma as:

"Feeling as though you can't provide for yourself or you can't take care of yourself. ... There's already kind of a stigma just in general with low income, low socioeconomic status, things of that nature."

Theme 3: Conversation Starters. Conversation starters is defined as a topic or visual that triggers conversation about food insecurity and health. Participants identified these conversation starters as something that would open the door to discuss this issue. CBO participants expressed the struggles that come with discussing health at the pantry. FMPC participants expressed the importance of having a lead-off point, such as talking about a program like WIC (USDA's Special Supplemental Nutrition Program for Women, Infants, and Children):

"Most of our patients have WIC and food share so we almost act like everybody does have it, as we always ask, 'Have you set your WIC up for babies yet?' and stuff like that."

Theme 4: Having the Answers. Participants, FMPC and $\mathrm{CBO}$ alike, spoke of a sense of feeling overwhelmed, even if a discussion of food insecurity took place. They lacked having answers, which was defined as an individual's knowledge of what to do when a problem presents itself, or that the current "answers" were not sufficient or robust enough. For example, a FMPC provider offered:

"I think for both the patient and the provider it's, okay, now we have uncovered this problem ... are they even gonna be able to help me with this? And you feel maybe guilty not knowing what you can actually do to help them. ... It seems like something that is almost like an unsolvable problem."

\section{Systemic Impact}

Theme 5: Safe Spaces. Creating a space to discuss sensitive topics defines "safe spaces." Participants discussed both a physical space and an emotional space. Both FMPC and CBO participants describe the need to create such a space within the setting. A CBO participant described how one $\mathrm{CBO}$ has strived to create such a space:

"We have a nice opportunity to get in touch with people and figure out what's wrong with them. We have their comfort and their trust in this space here 'cause everyone knows it's inclusive. We are an inviting place here."

Theme 6: Purposeful Training. Providers, particularly resident physicians early on in their training, spoke of the lack of adequate education and training around food insecurity in the clinic space. One resident physician also described how time pressures inhibited such training when discussing patient care with their supervising physician:

"From a learner perspective, if we go to staff a patient and assess[ing] food insecurity is required, no, because I don't have that hour now. I just spent 15 minutes to staff."

CBO participants also discussed their view on the importance of volunteer training and the hope to incorporate further training around stigma, food insecurity, health, and beyond.

\section{DISCUSSION}

The goal of this qualitative study was to understand the connections between primary care and community groups in addressing food insecurity and health. This is one of the first studies to investigate these issues from the perspectives of both FMPC providers and CBOs. The similarities in themes that arose identified areas of success and for improvement in each respective setting; yet, they also identified the disconnect between FMPC and CBO and opportunities to improve collaboration. Despite the similarities between the responses of the groups, there was a seeming lack of connection between the two.

As a similarity, the importance of meaningful relationships emerged as the core theme, both between FMPC provider and patient and between $\mathrm{CBO}$ and community member. A model indicating the centrality of meaningful relationships among FMPC providers, patients/pantry clients, and CBOs is illustrated in Figure 1. These relationships are bidirectional in that all must actively participate and contribute; this is also a central principal within

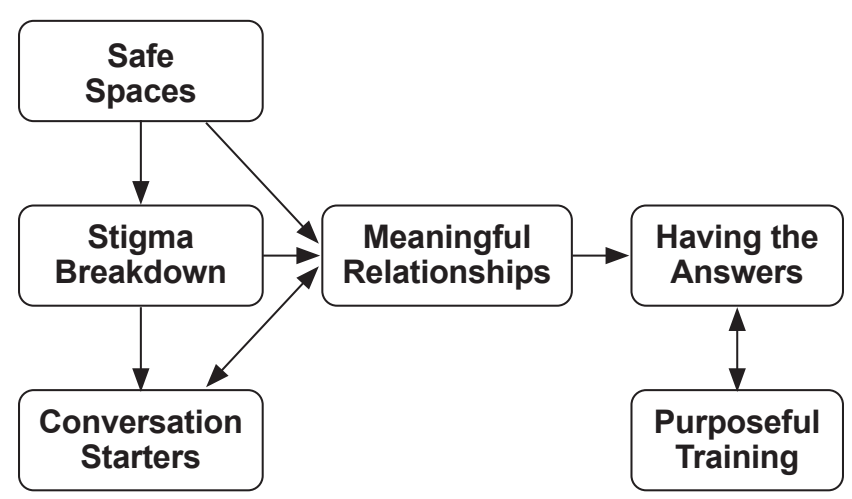

Figure 1. Model of family medicine/pediatric clinics and community-based organizations in addressing food insecurity and health. 
community engagement. ${ }^{29}$ Such relationships and shared experiences allow us to think beyond the separateness that often exists between FMPC and CBOs. It allows both patients and providers to express a level of vulnerability that often does not exist within the FMPC setting and can be lacking in the transactions of CBOs. The establishment and development of meaningful relationships is not solely the responsibility of one entity but a collaborative effort by all stakeholders. The lesson learned is we need to find tangible ways in which to communicate around the issue.

For example, if a meaningful relationship has not been established, participants - from both FMPC and CBOs - divulged certain tactics (ie, conversation starters) that facilitated the discussion of food insecurity and health. The lesson of intentionality, that trusted relationships do not occur all at once but require commitment by all to invest time to develop trust, needs to be recognized. The longer the relationship, the more likely trust is to be found, but trust must be earned at either setting. This is especially relevant and challenging in areas where multiple cultures are present. Both care providers and food pantries alike feel the pressure of time restraints, whether it is seeing enough patients or the need to be efficient and "get food out the door." Thus, intentionality is needed to create trusting relationships, otherwise the opportunity to connect at a meaningful level may be missed.

Additionally, to move forward in the relationship, all those involved need to recognize the stigma the issue holds, including stigma encountered by those who may have had negative experiences or faced judgments within the health care system, and work toward greater understanding. On a systemic level, this entails creating a safe and secure place to talk through these issues. As mentioned, one of the CBOs interviewed for this project is already successful in this regard.

There was a lack of connectedness between FMPC and CBOs despite the parallel in themes. Each could identify the important factors in addressing its respective "domain" (FMPC and health, CBO and food insecurity) but had limited ability to speak about how the organizations connected. Considering time constraints, a specific script or workflow may be required. Part of the workflow can be an intentional intersection in which the $\mathrm{CBO}$ can be used as the trusted link between FMPC and the client - a warm handoff between organizations. However, for this privileged relationship to occur, the CBO and FMPC need to build their own trusted link. This research reveals that the link between CBOs and FMPC is missing. FMPC providers may initiate a referral to a $\mathrm{CBO}$, but their knowledge of the $\mathrm{CBO}$ and its resources was severely limited. On the $\mathrm{CBO}$ side, these organizations have succeeded to create a space to discuss food insecurity and, potentially, health but do not have a clear pathway to provide answers for their clients' health. Though answers to all questions might not be available, a path between the CBO and FMPC would help. In the scope of addressing food insecurity, these vital players currently exist in silos. Rather than fully taking advantage of both their strengths, there is virtually no connection other than providing a name or a physical address. Greater intentionality and bidirectional connectivity between FMPC and CBO are needed.

Lastly, FMPC providers discussed fear of not "having the answers" if food security is brought up during clinic. Previous research indicates that there is not widespread screening by providers for food insecurity, nor are there standardized protocols in place for referring identified patients to community programs. ${ }^{9,10}$ This rang true during the focus groups, and FMPC providers explained this was due to the uncertainty of how to proceed. One FMPC did not have a social worker on site, and providers were unaware of resources. Even at a FMPC clinic with an onsite social worker, such individuals were overstretched, and providers had minimal knowledge of available resources. This gap in knowledge was further elucidated with discussion of lacking purposeful training for FMPC learners around the issue of food insecurity.

When asked about the role of food and health in participants' respective organizations, there was a perceptible pause and silence. The silence may infer meaning in both spaces. Food insecurity in the United States is a silent epidemic that all acknowledge exists, but without comprehensive and adequate solutions. Despite decades of the wellknown associations between food insecurity and health, and social determinants of health in general, this study demonstrated how, overall, FMPC did not talk about food and CBOs did not address health. ${ }^{39}$ Further research needs to be done to explain this disconnection. The COVID-19 pandemic will likely further elicit this need, as social determinants of health and social inequities can have a considerable effect on COVID-19 outcomes and social distancing adds barriers to food access. ${ }^{25}$ Now more than ever, FMPC and CBOs have the opportunity to build meaningful relationships to help their patients and clients address food insecurity and health.

\section{Limitations}

This study has a number of limitations. First, a purposive sample was employed based on existing relationships, which provides a limited perspective. Additionally, the sample included a variation of participation from FMPC and $\mathrm{CBO}$. There was variation in the years of experience and other roles that FMPC providers or $\mathrm{CBO}$ staff and 
clients held, thus varying the perspectives that arose during interviews. There is a need to include diverse and equitable perspectives in all research. Future interviews will further illuminate the current model and allow for balance between $\mathrm{CBO}$ and FMPC perspectives. Despite these limitations, the current research provides a more complete picture of the clinical and community perspective around food insecurity.

\section{CONCLUSIONS}

Food insecurity continues to affect the lives of millions in the United States. However, collaborative discussions of food status and health are not occurring at places where this population frequently interacts - primary care clinics and community-based organizations. This study provides insight into the current status of the relationship between FMPC and CBO in regard to addressing food insecurity and health, and highlights themes that may advise future communication and collaboration. First, representatives from FMPC and CBO must break the silence, actively discussing the issue of food security and health across their respective settings to cultivate meaningful relationships and link their individual strengths and assets. Second, the development of policies that provide solutions is needed. These may involve creating inclusive spaces, both the physical and emotional, in FMPC and CBO to break down stigma, allow for food- and healthrelated conversations, and foster relationships. Lastly, greater efforts are needed to educate future generations of health care providers to foster such relationships and address food insecurity in their clinical practice.

\section{Patient-Friendly Recap}

- Food insecurity - when a person may go hungry because their household lacks money or other resources - affects millions of Americans and has been exacerbated by the COVID-19 pandemic. This hardship is often lessened by local food pantries; however, food insecurity can still negatively affect health outcomes.

- The authors interviewed primary care providers and both staff and clients of food pantries to understand how each views their respective roles in addressing food insecurity.

-While similar themes emerged from both groups (such as the importance of establishing meaningful relationships and purposeful training), there remains considerable disconnect in action between primary care and community organizations.

- Breaking the silence in acknowledging food insecurity is the first step providers must take.

\section{Author Contributions}

Study design: all authors. Data acquisition or analysis: all authors. Manuscript drafting: all authors. Critical revision: all authors.

\section{Conflicts of Interest}

None.

\section{Funding Sources}

Funding was provided by Medical College of Wisconsin's Center for Healthy Communities and Research (Milwaukee, WI).

\section{References}

1. Coleman-Jensen A, Rabbitt MP, Gregory CA, Singh A. Household Food Security in the United States in 2017 [ERR-256]. U.S. Department of Agriculture, Economic Research Service; 2018. https://www.ers.usda.gov/webdocs/ publications/90023/err-256.pdf

2. Gundersen C. Food insecurity is an ongoing national concern. Adv Nutr. 2013;4:36-41. CrossRef

3. Gundersen C, Ziliak JP. Food insecurity and health outcomes. Health Aff (Millwood). 2015;34:1830-9. CrossRef

4. Hampton T. Food insecurity harms health, well-being of millions in the United States. JAMA. 2007;298:1851-3. CrossRef

5. Vercammen KA, Moran AJ, McClain AC, Thorndike AN, Fulay AP, Rimm EB. Food security and 10-year cardiovascular disease risk among U.S. adults. Am J Prev Med. 2019;56:689-97. CrossRef

6. Rabaut LJ. Medically tailored meals as a prescription for treatment of food-insecure type 2 diabetics. J Patient Cent Res Rev. 2019;6:179-83. CrossRef

7. Krist AH, Davidson KW, Ngo-Metzger Q, Mills J. Social determinants as a preventive service: U.S. Preventive Services Task Force methods considerations for research. Am J Prev Med. 2019;57(6 Suppl 1):S6-12. CrossRef

8. Schanzenbach D, Pitts A. Estimates of Food Insecurity During the COVID-19 Crisis: Results from the COVID Impact Survey, Week 1 (April 20-26, 2020). Institute for Policy Research Rapid Research Report; 2020. https://www.ipr.northwestern.edu/documents/ reports/food-insecurity-covid week1 report-13-may-2020.pdf

9. Daniel H, Bornstein SS, Kane GC; Health and Public Policy Committee of the American College of Physicians. Addressing social determinants to improve patient care and promote health equity: an American College of Physicians position paper. Ann Intern Med. 2018;168:577-8. CrossRef

10. Lundeen EA, Siegel KR, Calhoun H, et al. Clinical-community partnerships to identify patients with food insecurity and address food needs. Prev Chronic Dis. 2017;14:E113. CrossRef

11. Barnidge E, LaBarge G, Krupsky K, Arthur J. Screening for food insecurity in pediatric clinical settings: opportunities and barriers. J Community Health. 2017;42:51-7. CrossRef

12. Billioux A, Verlander K, Anthony S, Alley D. Standardized screening for health-related social needs in clinical settings: the accountable health communities screening tool. Discussion paper. National Academy of Medicine; 2017. CrossRef

13. Sokol R, Austin A, Chandler C, et al. Screening children for social determinants of health: a systematic review. Pediatrics. 2019;144:e20191622. CrossRef

14. Konrad TR, Link CL, Shackleton RJ, et al. It's about time: physicians' perceptions of time constraints in primary care medical practice in three national healthcare systems. Med Care. 2010;48:95-100. CrossRef 
15. Pooler JA, Hoffman VA, Karva FJ. Primary care providers' perspectives on screening older adult patients for food insecurity. J Aging Soc Policy. 2018;30(1):1-23. CrossRef

16. McAsey A, Rana P, Goschin Y, Sullivan Vedder L, Kram JF, Klumph M. Fruit and vegetable vouchers do not increase redemption or consumption. (abstr.) J Patient Cent Res Rev. 2020;7:358. CrossRef

17. Loopstra R. Interventions to address household food insecurity in high-income countries. Proc Nutr Soc. 2018;77:270-81. CrossRef

18. Food and Nutrition Service, U.S. Department of Agriculture. Facts about SNAP. Page last reviewed August 14, 2020; accessed March 2, 2020. https://www.fns.usda.gov/snap/facts

19. Ralston K, Treen K, Coleman-Jensen A, Guthrie J. Children's Food Security and USDA Child Nutrition Programs [EIB-174]. U.S. Department of Agriculture, Economic Research Service; 2017. https://www.ers.usda.gov/webdocs/publications/84003/ eib-174.pdf? $v=2094.7$

20. Ginsburg ZA, Bryan AD, Rubinstien EB, et al. Unreliable and difficult-to-access food for those in need: a qualitative and quantitative study of urban food pantries. J Community Health. 2019;44:16-31. CrossRef

21. Dunn CG, Kenney E, Fleischhacker SE, Bleich SN. Feeding low-income children during the Covid-19 pandemic. $N$ Engl $J$ Med. 2020;382:e40. CrossRef

22. Tarasuk V, Eakin JM. Charitable food assistance as symbolic gesture: an ethnographic study of food banks in Ontario. Soc Sci Med. 2003;56:1505-15. CrossRef

23. Daponte BO, Lewis GH, Sanders S, Taylor L. Food pantry use among low-income households in Allegheny County, Pennsylvania. J Nutr Educ. 1998;30:50-7. CrossRef

24. Feeding America. Map the Meal Gap 2010: A Report on County and Congressional District Food Insecurity and County Food Cost in the United States in 2017. Feeding America; 2019. https://www.feedingamerica.org/sites/default/files/201905/2017-map-the-meal-gap-all-modules_0.pdf

25. Abrams EM, Szefler SJ. COVID-19 and the impact of social determinants of health. Lancet Respir Med. 2020;8:659-61. CrossRef

26. Wilson MG, Lavis JN, Guta A. Community-based organizations in the health sector: a scoping review. Health Res Policy Syst. 2012;10:36. CrossRef

27. Wu AW, Weston CM, Ibe $\mathrm{C}$, et al. The Baltimore CommunityBased Organizations Neighborhood Network: Enhancing Capacity Together (CONNECT) cluster RCT. Am J Prev Med. 2019;57 e31-41. CrossRef
28. Stout SS, Simpson LA, Singh P. Trust between health care and community organizations. JAMA. 2019;322:109-10. CrossRef

29. Ahmed SM, Maurana C, Nelson D, Meister T, Young SN, Lucey P. Opening the black box: conceptualizing community engagement from 109 community-academic partnership programs. Prog Community Health Partnersh. 2016;10:51-61. CrossRef

30. Porterfield DS, Hinnant LW, Kane H, Horne J, McAleer $\mathrm{K}$, Roussel A. Linkages between clinical practices and community organizations for prevention: a literature review and environmental scan. Am J Public Health. 2012;102(Suppl 3):S375-82. CrossRef

31. Britten N. Qualitative interviews in medical research. BMJ. 1995;311:251-3. CrossRef

32. Chew-Graham CA, May CR, Perry MS. Qualitative research and the problem of judgment: lessons from interviewing fellow professionals. Fam Pract. 2002;19:285-9. CrossRef

33. Charmaz K. Grounded theory in the 21 st century: applications for advancing social justice studies. In: Denzin NK, Lincoln YS (eds). The Sage Handbook of Qualitative Research, Third Edition. Sage Publications; 2005, pp. 507-36.

34. Turato ER. [Qualitative and quantitative methods in health: definitions, differences and research subjects.] Rev Saúde Pública. 2005;39:507-14. CrossRef

35. Walker RE, Kusch J, Fink JT, Nelson DA, Morris G 3rd, Skalla J, Cisler RA. Facilitating factors and barriers to weight management in women: physician perspectives. J Patient Cent Res Rev. 2018;5:18-27. CrossRef

36. Waniger A, Gale K, DeNomie M, Nelson D. Community and caregiver perceptions of giving care to seniors. Int J Psychiatry Med. 2019;54:307-15. CrossRef

37. Harris A, Nelson D, Salas Harris K, Horner-Ibler B, Burns E. "We need a new normal": sociocultural constructions of obesity and overweight among African American women. In: Wright E 2nd, Wallace EV (eds). The Ashgate Research Companion to Black Sociology. Ashgate Publishing; 2015, pp. 177-92.

38. Nelson DA, Morzinski J, Flower M. The Milwaukee Continuum: older veterans and nonveterans use Housing First to exit homelessness. J Humanist Psychol. [Epub 2019 Aug 8]. CrossRef

39. Braveman P, Egerter S, Williams DR. The social determinants of health: coming of age. Annu Rev Public Health. 2011;32:381-98. $\underline{\text { CrossRef }}$

(C) 2021 Advocate Aurora Health, Inc. 